\title{
THE IMPACT OF IMPLICIT AND EXPLLIT TRAINING METHODS ON THE ACQUISTTION OF PEREEPTUAL EXPERTISE IN YOUNG ATHLETES
}

\author{
Afroditi Lola A, B, D \\ School of Physical Education, Aristotle University of Thessaloniki, Greece \\ ORCID: 0000-0002-1489-0628 | e-mail: afroditelola@yahoo.gr, alola@phed.auth.gr

\section{Evandros Votsis $\mathrm{A}, \mathrm{B}, \mathrm{D}$}

School of Physical Education, Aristotle University of Thessaloniki, Greece ORCID: 0000-0002-8468-685X

\section{George Tzetzis ${ }^{A, B, D}$}

School of Physical Education, Aristotle University of Thessaloniki, Greece ORCID: 0000-0002-9345-5826

\section{Dimitris Chatzopoulos ${ }^{\complement}$}

\author{
School of Physical Education, Aristotle University of Thessaloniki, Greece \\ ORCID: 0000-0001-5069-2613

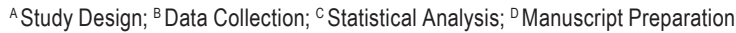

\begin{abstract}
Ahstract This study examined the effectiveness of implicit and explicit learning methods on the acquisition and retention of the decision-making skill in low and high complexity situations. 60 novice students were divided into explicit, implicit, and control group. Experimental groups followed 12 training courses. A pre-test, a post-test, and a retention test were used to evaluate the effectiveness of the instructional methods. All participants were evaluated in decision-making speed and accuracy in laboratory tests under simulated conditions. A three-way factorial ANOVA was conducted ( 3 Group X 2 Complexity X 3 Measurement periods) with repeated measurements on the last factor for the accuracy and reaction time. The analysis showed a significant improvement in decision-making accuracy, in low complexity for both experimental groups. In high complexity situations, the explicit method improved over time and was better than the implicit for decision accuracy. No differences were found among groups or measurements for the decision speed in either low or high complexity situations. It seems that in complex sport conditions, the use of explicit learning helps novices to develop decision-making accuracy more than the implicit learning method, since guided discovery may guide the participants to process contextual information from the sports environment more effectively.
\end{abstract}

Key World attention demands, decision-making, complexity, speed, accuracy, dual sports 


\section{Introduction}

Decision-making is the ability to make the right and quick decision and is important for athletes when performing a sport skill, especially in a changing environment such as in team sports (Lola, Tzetzis, 2020) or maybe in dual sports. In racket sports players have to make correct decisions for the direction of the ball according to their or their opponents' position on court within a very short time (Raab, 2005).

Many researchers have attempted to discover instructional methods that will improve perceptual expertise in sport; however, knowledge is sparse about when, whether, or how perceptual skills such as decision-making can be developed through instruction and practice (Votsis, Tzetzis, Hatzitaki, Grouios, 2009). Whilst the effectiveness of implicit and explicit learning strategies has been debated in the motor learning literature (Masters, 1992; Masters, Maxwell, 2004), few researchers have attempted to investigate whether the typical conclusions reported for motor skills also relate to perceptual and cognitive skills such as decision-making (Williams, Ward, Smeeton, 2004).

The explicit learning method is the most common training method, used by coaches especially for novices. In this instructional method, the coach sets out clear rules and gives verbal instructions on how to execute a particular movement or skill (Lola, Tzetzis, 2020). The acquisition of knowledge via the explicit learning process results in consciously accessible declarative knowledge that can be articulated (Tzetzis, Lola, 2010). However, the explicit use of rules places a heavy load on working memory resources. These limitations, under some conditions, will impede learning since working memory is extremely limited in both capacity and duration (Maxwell, Masters, Eves, 2003). When execution requires simultaneous processes of motor response and analyzes the environment using multiple sources of information to make the correct decision, the control system is overloaded and this may reduce sports performance (Maxwell, Masters, Eves, 2000).

According to the implicit learning method, the coach does not give instructions of execution but distracts the attention of the trainees using a secondary stimulus (Jackson, Farrow, 2005; Williams, Ward, Chapman, 2003; Votsis, Tzetzis, Hatzitaki, Grouios, 2009), to develop procedural knowledge, bypassing working memory processing (Masters, 1992; Kleynen et al., 2014). Thus, skills that are learned implicitly are thought to be less reliant on declarative knowledge than skills that are learned explicitly (Maxwell, Masters, Eves, 2000), and instead capitalize more strongly on automatic processes (Lola, Tzetzis, 2020; Chauvel et.al., 2012). The advantage of implicit practice is that working memory is not involved in the implicit process, which allows the athlete to perform other functions in parallel, such as decision-making (Baddeley, 2003). Research in the area of decision-making has demonstrated that implicit practice has a positive effect on developing and improving decision-making since it enables the use of multiple sources of information that help to make correct decisions (Tzetzis, Lola, 2010; Poolton, Maxwell, Masters, Raab, 2006; Jackson, Farrow, 2005; Smeeton, Williams, Hodges, Ward, 2005; Raab, 2003a; MacMahon, Masters, 2002).

The omission of explicit rules seems to have a positive effect on performance; however, the results of the performance depend on the complexity of the situations too (Maxwell et al., 2003; Liao, Masters, 2001). In more realistic scenarios, as in fast racket sports, the athletes are faced with dozens of complex situations. Raab (2005) mentions that several factors, such as movement efficiency, task complexity, uncertainty, and speed, influence the effectiveness of movements. Complexity in decision-making includes two dimensions that may exist simultaneously in the game: (a) the simultaneous demand on perception and motor response (tactical information), and (b) the game conditions, which can have an intense effect on both motor selection and execution of the appropriate response (e.g., Fitts, Posner, 1967). Regarding the first dimension (a), in real conditions, sports performance 
involves both motor and decision-making components translated into tactical information. Raab (2005) suggests that tactical information is characterized as complex and is usually supplied once movement production has been mastered. Raab (2003a) also suggests that a methodical description of game tactics is to categorize the complexity of the game (more difficulty - less difficulty) formed by the combination: stimulus - analysis and processing appropriate kinetic response. In another study, Raab (2003b) mentions that there is a distinction between motor skill learning versus cognitive skill learning. Masters, Poolton, Maxwell and Raab (2008) and Poolton, Masters, and Maxwell (2006) investigated the benefits of implicit learning on cognitive efficiency in a task involving both motor and decision-making components. They concluded that explicit learners exhibited performance decrements when performing a decision-making task and a high complexity task concurrently. The concept behind these techniques is based on the processing of declarative (acquisition via explicit methods) and procedural knowledge (acquisition via implicit methods) (Anderson, 1983; Fitts, Posner, 1967; Schneider, Schiffrin, 1977). As Raab (2005) mentions, the processing of declarative knowledge depends on limited attention resources, whereas procedural responses are less attention-demanding, and the point is to gradually free up attention resources that can then be devoted to more complex variations of the skill. However, several researchers argue that is possible to achieve parallel development of declarative and procedural knowledge (e.g., Gentile, 1998; Raab, Masters, Maxwell,2005; Maxwell, Masters, Eves, 2003) and hint that a combination of decision and behavioral training may be beneficial. The second dimension (b) is the game conditions, which are determined by the variety of stimuli and responses in each environment (Siemann, Gebhardt, 1996). The complexity of the game conditions can also take other forms, such as the time available to perform the skill, the emotional charge of the participant (Masters, 1992), or the analysis of the primary and secondary goals (DeShon, Alexander, 1996). Raab (2003a) also states that the degree of complexity of a gaming condition increases as the number of options increases, while the detection time of stimuli decreases. Additionally, Raab (2003a) identified that the degree of decision-making complexity depends on game conditions $1 \mathrm{~V} 1,2 \mathrm{~V} 2,3 \mathrm{~V} 3,4 \mathrm{~V} 4$. Conditions one against one $-1 \mathrm{~V} 1$, and two against two $-2 \mathrm{~V} 2$ were characterized as low complexity game conditions. Conditions three versus three $-3 \mathrm{~V} 3$ and four versus four $-4 \mathrm{~V} 4$ were characterized as conditions of high complexity.

Very few studies (Masters et al.2008; Jackson, Farrow, 2005; Raab, 2003a, b; Gomez, 1997) examined the effect of instruction methods on the improvement of decision-making in different task complexity conditions. The present study compared directly some of the most common techniques on perceptual training -the explicit and implicit method of instruction, in different complexity situations. A novelty is that in the present study participate young athletes.

It was hypothesized that both implicit or explicit methods would positively affect the decision-making task in terms of reaction time and accuracy - in low complexity conditions; however, taking the literature into account (Lola, Tzetzis, 2021; Raab, 2003a; Smeeton, Williams, Hodges, Ward, 2005; Tzetzis, Lola, 2015; Masters, Maxwell, 2004), we expected the implicit method of learning to have better results in high complexity conditions, in a decisionmaking task.

\section{Material and methods}

Participants

The sample consisted of 63 students, aged 11 to 12 years $(M=11.5, S D=0.5) .42$ were girls and 21 were boys. All participants were perfectly healthy with no serious eye disorders. Participants were divided into three equal 
groups ( $\mathrm{N}=20$ ). Two groups were experimental (explicit and implicit learning), and the third was the control group (Farrow, Abernethy, 2002). All participants were beginners, with no previous experience of racket sports. Their parents signed a consent form and they were enrolled in the program with the right to retire at any stage. All rules of ethics and the anonymity of the participants were followed throughout the investigation.

\section{Research design}

All participants performed an initial measurement (pre-test). The experimental groups then followed the intervention program (12 courses: three times a week for four weeks). The post-test followed and, two weeks later, the retention test was implemented. All tests were laboratory tests in simulated playing conditions in badminton. Independent variables were the groups with three levels (explicit, implicit, and control group), the measurement with three levels (pre-test, post-test, retention test), and the complexity of the game conditions with two levels (low and high complexity). Dependent variables were a) the accuracy of the responses / total number of attempts X 100 and b) the reaction time (in $\mathrm{msec}$ ).

\section{Testing procedure}

In each test (pre-test, post-test, retention test), there was a trained person who verbally explained the test procedures, gave additional written instructions, and demonstrated the laboratory tests. To assess the ability to make decisions in low-complexity game conditions, 23 video game phases with different game-phase conditions were presented to the participants on a large screen through a projector (Smeeton, Williams, Hodges Ward, 2005). The first three attempts were trials and then the participants had 20 attempts to respond accurately and speedily. The videos lasted from 3.5 to 5 seconds and presented a game condition. The instruction on how to decide on options was balanced for speed-accuracy effects ("decide as quickly and accurately as possible"). The participants watched two athletes in a badminton court, and they had to assume that they were the athlete facing the participant, who was about to perform a badminton serve. The video stopped one frame before the hit. The participants had to react, by stepping (front or back) on a platform according to where it would be better in their view to serve in court. For the low complexity conditions, there were only two possible responses (Gomez, 1997; Raab, 2003a), while for the high complexity, the possible responses were six - each area in the video corresponding to a specific area on the platform. Particular attention was always paid to the participant, to ensure that they would not predict the hit but react according to they believed would be best for them to do. Thus, the decision-making but not the anticipation skill was assessed. The accuracy and speed of the response were evaluated.

\section{Intervention program}

The experimental groups attended 12 training courses which included theoretical $(20 \mathrm{~min})$ and practical phases (30 min), three times a week, for four weeks, following a different method (implicit or explicit) to improve their decision-making skill in badminton.

During the theoretical courses of the explicit group, the participants were given verbal explicit rules and written instructions regarding: a) the kinematic characteristics of the movement (Paup, Fernhall, 2000), b) instructions for the concentration of attention on the key points of the movement (Starkes, Deakin, JLindley, Crisp, 1987; Farrow, Abernethy, 2002), c) a brief report on the differences between experts and novices in decision-making strategies (Abernethy, Gill, Parks, Packer, 2001). They also watched videos with expert athletes and received feedback on 
right or wrong decision-making (Starkes, Lindley, 1994). None of the videos used in the tests were used during the training period and vice versa. During the theoretical courses, the implicit group did not receive any explicit instructions on decision-making skill, but they were instructed to watch the videos and memorize the decisionmaking tactical scenarios like a memory game. None of the videos used in the tests were used during the training period and vice versa. The situations, the options, and the number of correct and incorrect decisions were balanced for the training procedure so that the videos presented the same number of correct and incorrect decisions for all options.

During the practical courses, the explicit group followed the guided discovery learning method (Smeeton, Williams, Hodges, Ward, 2005), which contained instructions for the participant to pay attention to key points regarding how to perform the skill and its result. For each verbal instruction related to a key point of the skill, a question was asked about how these points were related to the result of the skill. An example is "Observe the direction of the racket at the time of the racket-shuttle contact, where do you think the shuttle will go?" The implicit group was trained via a secondary dual cognitive task through random letter generation (MacMahon, Masters, 2002; Gröpel, Mesagno, 2017). The participants had to respond and simultaneously indicate the next letter of the alphabet that was presented to them (dual-task). The control group did not take any theoretical or practical training.

\section{Statistics}

A three-way factorial ANOVA was conducted (3 Group X 2 Complexity X 3 Measurement periods) with repeated measurements on the last factor for the accuracy and reaction time of the decision. A post-hoc Tukey test was used to analyze significant differences $(p<0.05)$. The required sample size was calculated a priori with the help of G-power software (v. 3.1.9.7). For three groups and three measurements, with effect size 0.25 , alpha error 0.05 and power 0.8 the suggested minimum sample was 36 . Therefore the study's sample of 63 was deemed sufficient for the analysis. The criteria of Field (2019) were utilized in order to assess normality based on the calculation of Z Skewness and Z Kurtosis. The normality assumption was not violated for any of the study's variables.

\section{Results}

\section{The accuracy of the decision-making skill}

Mauchly's W was found to be significant $(\mathrm{W}(2)=0.470, \mathrm{p}<0.001)$ and Greenhouse-geisser statistic was below 0.75 (0.654) therefore the Greenhouse-Geiser correction was applied. The main effect and interaction analysis of the accuracy of the decision-making skill showed that there was a statistically significant main effect among the three measurement periods $\left(F_{(1.307,156.852)}=291.338, p<0.001\right.$, Partial $\left.\eta^{2}=0.708\right)$, the two degrees of complexity $\left(F_{(1,120)}=99.190, p<0.001\right.$, Partial $\left.\eta^{2}=0.453\right)$, and the three groups $\left(F_{(2,120)}=20.530, p<0.001\right.$, Partial $\left.\eta^{2}=0.255\right)$. There was statistically significant interaction $\left(F_{(2.614,156.852)}=100.970, p<0.001\right.$, Partial $\left.\eta^{2}=0.627\right)$ among the three measurement periods and the three groups, the two degrees of complexity and the three groups $\left(F_{(2,120)}=7.150\right.$, $p=0.001$, Partial $\left.\eta^{2}=0.106\right)$, the measurement periods and the complexity $\left(F_{(1.307,156.852)}=47.813, p<0.001\right.$, Partial $\left.\eta^{2}=0.285\right)$. Finally, there was also a statistically significant interaction $\left(F_{(2.614,156.852)}=19.497, p<0.001\right.$, Partial $\left.\eta^{2}=0.245\right)$ among the measurement periods, the groups, and the complexity. The mean accuracy of the decisionmaking skill is depicted in Table 1. 
Table 1. Mean accuracy (\%) of the decision-making skill

\begin{tabular}{|c|c|c|c|c|c|}
\hline Measurement & Complexity & Group & Mean & SD & Post hoc \\
\hline \multirow{8}{*}{ Pre-Test } & \multirow{4}{*}{ Low } & explicit & 40.00 & 4.18 & \multirow{4}{*}{$\begin{array}{c}E=I=C \\
F(2,31.964)=2.135, p=0.135 \\
\text { (Welch Anova, Games-Howell) }\end{array}$} \\
\hline & & implicit & 40.95 & 13.00 & \\
\hline & & control & 45.48 & 11.28 & \\
\hline & & total & 42.14 & 10.35 & \\
\hline & \multirow{4}{*}{ High } & explicit & 33.81 & 6.87 & \multirow{4}{*}{$\begin{array}{c}E=I=C \\
F(2,60)=0.381, p=0.685 \\
\text { (Fisher's Anova, Tukey HSD) }\end{array}$} \\
\hline & & implicit & 32.86 & 5.82 & \\
\hline & & control & 34.76 & 8.29 & \\
\hline & & total & 33.81 & 7.00 & \\
\hline \multirow{8}{*}{ Post-Test } & \multirow{4}{*}{ Low } & explicit & 63.81 & 7.05 & \multirow{4}{*}{$\begin{array}{c}E=I, E>C d=1.84, I>C d=1.57 \\
F(2,60)=22.123, p<0.001 \\
(\text { Fisher's Anova, Tukey HSD) }\end{array}$} \\
\hline & & implicit & 63.10 & 9.93 & \\
\hline & & control & 46.19 & 11.61 & \\
\hline & & total & 57.70 & 12.60 & \\
\hline & \multirow{4}{*}{ High } & explicit & 53.81 & 6.31 & \multirow{4}{*}{$\begin{array}{c}E>I d=3.00, E>C d=2.78, I=0 \\
F(2,60)=55.138, p<0.001 \\
(\text { Fisher's Anova, Tukey HSD) }\end{array}$} \\
\hline & & implicit & 35.48 & 5.90 & \\
\hline & & control & 32.62 & 8.75 & \\
\hline & & total & 40.63 & 11.76 & \\
\hline \multirow{8}{*}{ Retention Test } & \multirow{4}{*}{ Low } & explicit & 60.48 & 7.23 & \multirow{4}{*}{$\begin{array}{c}E=I, E>C d=1.48, I>C d=1.53 \\
F(2,60)=17.747, p<0.001 \\
(\text { Fisher's Anova, Tukey HSD) }\end{array}$} \\
\hline & & implicit & 62.86 & 10.07 & \\
\hline & & control & 46.19 & 11.61 & \\
\hline & & total & 56.51 & 12.17 & \\
\hline & \multirow{4}{*}{ High } & explicit & 51.90 & 7.50 & \multirow{4}{*}{$\begin{array}{c}E>I d=2.61, E>C d=2.58, I=C \\
F(2,60)=49.540, p<0.001 \\
(\text { Fisher's Anova, Tukey HSD) }\end{array}$} \\
\hline & & implicit & 35.00 & 5.24 & \\
\hline & & control & 31.90 & 7.98 & \\
\hline & & total & 39.60 & 11.23 & \\
\hline
\end{tabular}

\section{The reaction time of the decision-making skill}

Mauchly's W was found to be significan $(\mathrm{W}(2)=0.629, \mathrm{p}<0.001)$ and Greenhouse-geisser statistic was below $0.75(0.73)$ therefore the Greenhouse-Geiser correction was applied. The main effect and interaction analysis of the reaction time of the decision-making skill showed a statistically significant main effect among the three measurement periods $\left(F_{(1.459,175.092)}=10.807, p<0.001\right.$, Partial $\left.\eta^{2}=0.083\right)$ as well as between the two degrees of complexity $\left(F_{(1,120)}=7.562, p=0.007\right.$, Partial $\left.\eta^{2}=0.059\right)$. However there was no statisticaly significant effect between the three groups $\left(F_{(2,120)}=0.14, p=0.869\right.$, Partial $\left.\eta^{2}=0.002\right)$. There was no statistically significant interaction $\left(F_{(2.918,175,092)}=0.698 p=0.550\right.$, Partial $\left.\eta^{2}=0.012\right)$ between the three measurement periods and the three groups, the two degrees of complexity, and the groups $\left(F_{(2,120)}=1.172, p=0.313\right.$, Partial $\left.\eta^{2}=0.019\right)$, the measurement periods and the complexity $\left(F_{(1.459,175.092)}=0.145, p=0.797\right.$, Partial $\left.\eta^{2}=0.001\right)$. Finally, there was no statistically significant interaction $\left(F_{(2.918,175.092)}=0.209, p=0.885\right.$, Partial $\left.\eta^{2}=0.003\right)$ among the measurement periods, the groups, and the complexity. The mean reaction time of the decision-making skill is depicted in Table 2. 
Tahle 2. Mean reaction time (msec) of the decision-making skill

\begin{tabular}{|c|c|c|c|c|c|}
\hline Measurement & Complexity & Group & Mean & SD & Post hoc \\
\hline \multirow{8}{*}{ Pre-Test } & \multirow{4}{*}{ low } & explicit & $2,879.80$ & 599.17 & \multirow{4}{*}{$\begin{array}{c}E=I=C \\
F_{(2,60)}=0.148, p=0.863 \\
\text { (Fisher's Anova, Tukey HSD) }\end{array}$} \\
\hline & & implicit & $2,892.80$ & 469.13 & \\
\hline & & control & $2,970.30$ & 662.30 & \\
\hline & & total & $2,914.30$ & 574.38 & \\
\hline & \multirow{4}{*}{ high } & explicit & $3,115.60$ & 877.42 & \multirow{4}{*}{$\begin{array}{c}E=I=C \\
F_{(2,36.828)}=1.353, p=0.271 \\
\text { (Welch Anova, Games-Howell) }\end{array}$} \\
\hline & & implicit & $3,316.85$ & 428.83 & \\
\hline & & control & $3,050.00$ & 661.54 & \\
\hline & & total & $3,160.82$ & 679.66 & \\
\hline \multirow{8}{*}{ Post-Test } & \multirow{4}{*}{ low } & explicit & $2,714.70$ & 494.96 & \multirow{4}{*}{$\begin{array}{c}E=I=C \\
F_{(2,60)}=0.772, p=0.467 \\
\text { (Fisher's Anova, Tukey HSD) }\end{array}$} \\
\hline & & implicit & $2,672.70$ & 458.35 & \\
\hline & & control & $2,885.10$ & 760.19 & \\
\hline & & total & $2,757.50$ & 584.62 & \\
\hline & \multirow{4}{*}{ high } & explicit & $2,979.55$ & 624.64 & \multirow{4}{*}{$\begin{array}{c}E=I=C \\
F_{(2,60)}=0.084, p=0.920 \\
\text { (Fisher's Anova, Tukey HSD) }\end{array}$} \\
\hline & & implicit & $3,037.60$ & 396.61 & \\
\hline & & control & $2,972.85$ & 637.58 & \\
\hline & & total & $2,996.67$ & 555.51 & \\
\hline \multirow{8}{*}{ Retention Test } & \multirow{4}{*}{ low } & explicit & $2,661.10$ & 470.49 & \multirow{4}{*}{$\begin{array}{c}E=I=C \\
F_{(2,60)}=1.134, p=0.328 \\
\text { (Fisher's Anova, Tukey HSD) }\end{array}$} \\
\hline & & implicit & $2,655.45$ & 462.17 & \\
\hline & & control & $2,857.90$ & 550.72 & \\
\hline & & total & $2,724.82$ & 497.14 & \\
\hline & \multirow{4}{*}{ high } & explicit & $3,002.45$ & 674.34 & \multirow{4}{*}{$\begin{array}{c}E=I=C \\
F_{(2,60)}=0.678, p=0.511 \\
\text { (Fisher's Anova, Tukey HSD) }\end{array}$} \\
\hline & & implicit & $3,114.15$ & 415.00 & \\
\hline & & control & $2,900.75$ & 656.47 & \\
\hline & & total & $3,005.78$ & 590.75 & \\
\hline
\end{tabular}

\section{Discussion}

There are shreds of evidence showing that the implicit learning method is more effective than the explicit, in perceptual skills such as decision-making skills (Lola, Tzetzis, 2021; Poolton, Masters, Maxwell, 2006; Raab, 2003a, b). The present study aimed to examine the effect of explicit and implicit learning methods of instruction on the accuracy and speed of the decision-making skill, for novice badminton athletes in different levels of complexity. Limited studies evaluated directly the two training methods on the development of decision-making skill, using young participants (Lola, Tzetzis, 2021).

\section{Accuracy among groups and measurements measurements in low and high complexity situations}

In low complexity situations comparison among measurements showed that both the implicit and the explicit group improved over time their accuracy from the pre-test to the post-test and maintained their performance in the retention test. The control group did not appear to have any significant difference between the measurements. Similar results were found by Raab (2003a). The comparison among groups in the retention test showed that both the implicit and the explicit groups were more accurate than the control group. It seems that both the explicit (conscious) and the implicit (unconscious) learning method improve the accuracy of the responses. 
More specifically, in low complexity situations, the accuracy of the responses of the explicit group improved, possibly because the declarative knowledge acquired provided specific, relatively stable goals in well-defined tasks. The participants of the explicit group, based on the game conditions presented to them theoretically, analyzed the key points of the environment and the opponent, recalled the correct response from memory and selected the best solution. Vickers, Reeves, Chambers, Martell, (2004) state that explicit knowledge helps participants to create the procedure to discover the correct response.

The implicit learning group also improved its decision-making accuracy. Raab and Johnson (2008) explain that the implicit learning method results in the knowledge of situation-action relations that cannot be verbalized. This knowledge may lead to the improvement of decision-making accuracy. Masters, Law, and Maxwell (2002) assert that implicit cognitive learning helps to build judgments about the relation between stimuli and what movement should be carried out.

There was no difference in the accuracy of the decision-making skill between the explicit and implicit group. It seems that both methods allowed the participants to create a set of decision-making processes differently and respond accurately. Raab (2003a, b) also reported that both implicit and explicit processes may lead to improvements in decision-making skills. Raab and Johnson (2008) explain that the distinction between implicit and explicit learning plays a key role in the first two stages of Orasanu's and Connolly's (1993) protocol, which is: a) the presentation of the problem, and b) the identification of the constraints, resources, and goals. The presentation of the problem is the focus of a great deal of research on judgment and decision-making (e.g., Tversky, Kahneman, 1981), and the next step is the identification of the constraints, resources, and goals. The combination of theoretical courses (the presentation of videos, the photos highlighting technical points of the skill, the photos focusing on the tactics of the game), and the practical training, possibly improved critical thinking and developed the appropriate knowledge of the participants implicitly or explicitly, especially in the low complexity situation.

The advantage of the implicit over the explicit method is that it does not overload WM. In this research, the participants performed an easy, low attention demand task (choose between only two responses) in an easy condition, which was to step in the correct direction without executing any particular movement form. Raab (2003a) argued that implicitly learned decisions are advantageous in low-complexity situations; however, he used the traditional explicit learning method with possibly more attention demands. In this research, the explicit learning group followed the guided discovery method, which uses fewer attention resources compared to the traditional explicit learning method, and this might be another reason for the different results. It is concluded that both implicit and explicit processes are effective for decision accuracy in low complexity situations.

In high complexity situations the retention test results showed that in high complexity situations the explicit learning group was more accurate than the implicit group and both of them were better than the control group. Also, only the explicit group seemed to show an improvement over time. Possibly, the verbal guidance through the explicit (guided discovery) method helped novice participants to judge what information they should focus on or ignore, and to focus on the regulatory points of the environment or the players. The implicit learning mechanism of judgment in high complexity situations was not as helpful as the verbal instructions acquired through the guided discovery method. Raab (2002) also found similar results: in high complexity situations, the explicit process leads to better decisions than the implicit process. In another study, Raab (2003a) also argues that in high-complexity situations explicit learning enhances a selection of the necessary stimuli and uses these to make judgments about which option is the best. According to Magill (1998), in the complex environment of sports, athletes should be guided 
to "information-rich areas" to decide correctly. Explicit instructions could direct the attention of the novices to the information-rich or significant areas, leading to accurate decisions. This basic finding was also reported by Raab (2003b) in different sports (basketball, handball, volleyball) in which allocation decisions had to be made quickly. However, Raab et al. (2005) found contradictory results in another study using elite athletes. More specifically, they found that the unconscious mechanism (implicit) was better than the conscious (explicit) in complex situations such as a series of strokes in different playing conditions. The difference with the present study is probably due to the participants' level of expertise, since our participants were novices, so the level of expertise is probably a mediating factor. It is concluded that in high complexity situations when training novices, the application of the explicit learning method is better than the implicit learning method. However, several researchers (Bennet, 2000; Beek, 2000; Masters, 2012; Jackson, Farrow, 2005) have claimed that when training elite athletes, the application of the implicit learning method may be as or even more effective than the explicit learning method. Future studies should examine the effect of these two methods on different expertise levels.

\section{Reaction time among groups and measurements in low and high complexity situations}

The decision-making speed did not improved over time and there were no differences among the groups in low or high complexity situations. One possible explanation may be that even if novice participants were instructed to react fast and correctly, they probably tried to respond correctly as a matter of priority and did not improve the speed of their decision. Speed-accuracy effects between groups could not be found, as expected, due to the balanced instructions to decide as quickly and accurately as possible; however, it seems that they probably placed more emphasis on the correctness of their decisions than their speed. The participants were novices following 12 training sessions and they probably considered it more important to decide correctly than quickly. If the training were longer and they felt more confident recognizing known patterns, perhaps their decision speed would improve.

Another crucial point is that their reaction with their whole-body movement might increase the complexity of the situation even in the easy condition. The participants had to respond quickly by stepping on a platform with their lower limbs using multiple degrees of freedom to coordinate their whole body, increasing the complexity and speed of the response. Even if the task was easy (two choices), the whole body reaction seemed to be difficult. The lower limb response involved a whole-body motor response, which resulted in a considerable increase in reaction time, while the coordination and control of the body required the activation of even more muscles.

The results of the present study are also supported by previous research on perceptual skills where the accuracy of the response in the experimental group was improved but the reaction time was not, in sports such as volleyball (Adolphe, Vickers, Laplante, 1997), football (Franks, Hanvey, 1997) various skills in squash (Abernethy, Wood, Parks, 1999), and American football (Christina, Baressi, Shaffner, 1990).

\section{Conclusions}

It seems that in complex sport conditions when the environment is constantly changing and there is the possibility of multiple motor response options, the use of verbal instruction through guided discovery helps to develop decision-making accuracy more than the implicit learning method. The explicit learning method was found to be better compared to the implicit learning method, in young novice athletes, for decision accuracy but not for decision speed. It seems that the guided discovery learning method is an effective method of learning for novice athletes. Additionally, both implicit and explicit learning methods were effective for decision-making accuracy in low 
complexity conditions which means that there is no "process-pure approach". Neither the explicit nor the implicit learning method had any effect on the speed of decision for the novice participants. The level of expertise probably affects the effectiveness of these methods. Before deciding on the best training method to follow to improve decision-making, the level of complexity and the athletes' expertise must be taken into account.

\section{Limitations}

The results should be generalized with caution since the simulated evaluation process in the laboratory included creating self-produced video clips selected by three experts as being most typical of real situations. It is not certain that we would have the same results if the evaluation were done on the field. Secondly, the platform used in the laboratory may have increased the complexity of the conditions. No simulation can $100 \%$ match the real conditions and what the athlete experiences on the field. Field measurements enhance ecological validity and perhaps give a better picture of the effectiveness of practice methods (Lola, Tzetzis, 2021), and are recommended in future studies. Finally, the participants in this study were tested on a dual sport (badminton) with two opponents, and results may be different in team sports with more players.

\section{References}

Abernethy, B., Russell, D.G. (1987). The relationship between expertise and visual search strategy in a racquet sport. Human Movement Science, 6 (4), 283-319.

Abernethy, B., Gill, D.P., Parks, S.L., Packer, S.T. (2001). Expertise and the perception of kinematic and situational probability information. Perception, 30 (2), 233-252.

Abernethy, B., Wood, J.M., Parks, S. (1999). Can the anticipatory skills of experts be learned by novices? Research Quarterly for Exercise and Sport, 70 (3), 313-318.

Adolphe, R.M., Vickers, J.N., Laplante, G. (1997). The effects of training visual attention on gaze behaviour and accuracy: A pilot study. International Journal of Sports Vision, 4b (1), 28-33.

Anderson, J.R. (1983). Cognitive science series. The architecture of cognition.

Baddeley, A. (2003). Working memory: looking back and looking forward. Nature Reviews Neuroscience, 4 (10), 829-839.

Baddeley, A. (2007). Working Memory, Thought, and Action (Vol. 45). OuP Oxford.

Bard, C., Fleury, M., Goulet, C. (1994). Relationship between perceptual strategies and response adequacy in sport situations. International Journal of Sport Psychology.

Beek, P.J. (2000, October). Toward a theory of implicit learning in the perceptual-motor domain. In Scientific Sport Psychology Workshop, Nov, 1997, Amsterdam, Netherlands. Edizioni Luigi Pozzi.

Bennett, S.J. (2000). Implicit learning: Should it be used in practice? International Journal of Sport Psychology, 31, 542-546.

Carruthers, P. (2013). Mindreading in infancy. Mind \& Language, 28 (2), 141-172.

Chauvel, G., Maquestiaux, F., Hartley, A.A., Joubert, S., Didierjean, A., Masters, R.S. (2012). Age effects shrink when motor learning is predominantly supported by nondeclarative, automatic memory processes: Evidence from golf putting. Quarterly Journal of Experimental Psychology, 65 (1), 25-38.

Christina, R.W., Barresi, J.V., Shaffner, P. (1990). The development of response selection accuracy in a football linebacker using video training. The Sport Psychologist, 4 (1), 11-17.

Cowan, N. (2016). Working Memory Capacity: Classic edition. Psychology press.

DeShon, R.P., Alexander, R.A. (1996). Goal setting effects on implicit and explicit learning of complex tasks. Organizational Behavior and Human Decision Processes, 65 (1), 18-36.

Engle, R.W. (2010). Role of working-memory capacity in cognitive control. Current Anthropology, 51 (S1), S17-S26.

Farrow, D., Abernethy, B. (2002). Can anticipatory skills be learned through implicit video based perceptual training? Journal of Sports Sciences, 20 (b6), 471-485. 
Fitts, P.M., Posner, M.I. (1967). Human Performance.

Franks, I.M., Hanvey, T. (1997). Cues for goalkeepers. High-tech methods used to measure penalty shot response. Soccer Journal, $42,30-33$.

Gentile, A.M. (1998). Movement science: Implicit and explicit processes during acquisition of functional skills. Scandinavian Journal of Occupational Therapy, 5 (1), 7-16.

Gomez, R.L. (1997). Transfer and complexity in artificial grammar learning. Cognitive Psychology, 33 (2), 154-207.

Gröpel, P., Mesagno, C. (2017). Choking interventions in sports: A systematic review. International Review of Sport and Exercise Psychology, 12 (1),1-26.

Helsen, W.F., Starkes, J.L. (1999). A new training approach to complex decision making for police officers in potentially dangerous interventions. Journal of Criminal Justice, 27 (5), 395-410.

Jackson, R.C., Farrow, D. (2005). Implicit perceptual training: How, when, and why? Human Movement Science, 24 (3), $308-325$.

Kleynen, M., Braun, S.M., Bleijlevens, M.H., Lexis, M.A., Rasquin, S.M., Halfens, J., Wilson, M.R., Beurskens, A.J., Masters, R.S. (2014). Using a Delphi technique to seek consensus regarding definitions, descriptions and classification of terms related to implicit and explicit forms of motor learning. PLoS One, 9 (6), e100227.

Liao, C.M., Masters, R.S. (2001). Analogy learning: A means to implicit motor learning. Journal of Sports Sciences, 19 (5), $307-319$.

Lola, A.C., Tzetzis, G.C. (2021). The effect of explicit, implicit and analogy instruction on decision making skill for novices, under stress. International Journal of Sport and Exercise Psychology, 1-21.

Lola, A.C, Tzetzis, G. (2020). Analogy versus explicit and implicit learning of a volleyball skill for novices: The effect on motor performance and self-efficacy. Journal of Physical Education and Sport, 20, 2478-2486.

MacMahon, K., Masters, R.S. (2002). The effects of secondary tasks on implicit motor skill performance. International Journal of Sport Psychology.

Magill, R.A. (1998). Knowledge is more than we can talk about: Implicit learning in motor skill acquisition. Research Quarterly for Exercise and Sport, 69 (2), 104-110.

Masters, R.S. (2012). Advances in implicit motor learning. In Skill acquisition in sport, 85-102, Routledge.

Masters, R.S. (1992). Knowledge, knerves and know-how: The role of explicit versus implicit knowledge in the breakdown of a complex motor skill under pressure. British Journal of Psychology, 83 (3), 343-358.

Masters, R.S.W., Poolton, J.M., Maxwell, J.P., Raab, M. (2008). Implicit motor learning and complex decision making in time-constrained environments. Journal of Motor Behavior, 40 (1), 71-79.

Masters, R.S., Maxwell, J.P. (2004). 10 Implicit motor learning, reinvestment and movement disruption. Skill Acquisition in Sport: Research, theory and practice, 207.

Masters, R., Law, J., Maxwell, J. (2002). Implicit and explicit learning in interceptive actions. Interceptive Actions in Sport: Information and movement, 126-143.

Maxwell, J.P., Masters, R.S.W., Eves, F.F. (2003). The role of working memory in motor learning and performance. Consciousness and Cognition, 12 (3), 376-402.

Maxwell, J.P., Masters, R.S., Eves, F.F. (2000). From novice to no know-how: A longitudinal study of implicit motor learning. Journal of sports sciences, $18(2), 111-120$.

Orasanu, J., Connolly, T. (1993). The reinvention of decision making. Decision Making in Action: Models and methods, 1, 3-20.

Paup, C.D., Fernhall, B. (2000). Skills, Drills and Strategies for Badminton. Arizona: Holcomb Hathaway Publishers.

Poolton, J.M., Masters, R.S., Maxwell, J.P. (2006). The influence of analogy learning on decision-making in table tennis: Evidence from behavioural data. Psychology of sport and exercise, 7 (6), 677-688.

Poolton, J.M., Maxwell, J.P., Masters, R.S.W., Raab, M. (2006). Benefits of an external focus of attention: Common coding or conscious processing? Journal of Sports Sciences, 24 (1), 89-99.

Raab, M. (2002). T-ECHO: Model of decision making to explain behaviour in experiments and simulations under time pressure. Psychology of Sport and Exercise, 3 (2), 151-171.

Raab, M. (2003a). Decision making in sports: Influence of complexity on implicit and explicit learning. International Journal of Sport and Exercise Psychology, 1 (4), 406-433.

Raab, M. (2003b). Implicit and Explicit Learning of Decision Making in Sports is Effected by Complexity of Situation. International Journal of Sport Psychology. 
Raab, M. (2005). An explicit investigation of implicit decision-making processes. International Journal of Sport and Exercise Psychology, $3(1), 91-97$.

Raab, M., Johnson, J.G. (2008). Implicit learning as a means to intuitive decision making in sports.

Raab, M., Masters, R.S., Maxwell, J.P. (2005). Improving the 'how' and 'what' decisions of elite table tennis players. Human Movement Science, 24 (3), 326-344.

Savelsbergh, G.J., Van der Kamp, J., Williams, A.M., Ward, P. (2005). Anticipation and visual search behaviour in expert soccer goalkeepers. Ergonomics, 48 (11-14), 1686-1697.

Schneider, W., Schiffrin, R.M. (1977). Automatic vs controlled processing. Psychol Rev, 84, 1-64.

Siemann, M., Gebhardt, R.P. (1996). Einfluss der Instruktion und Aufgabenkomplexität auf transitive Entscheidungen (Effects of instructions und task complexity in transitive decisions). Zeitschrift für Experimentelle Psychologie, 2, 435-460.

Smeeton, N.J., Williams, A.M., Hodges, N.J., Ward, P. (2005). The relative effectiveness of various instructional approaches in developing anticipation skill. Journal of Experimental Psychology: Applied, 11 (2), 98.

Starkes, J.L., Lindley, S. (1994). Can we hasten expertise by video simulations? Quest, 46 (2), 211-222.

Starkes, J.L., Deakin, J.M., Lindley, S., Crisp, F. (1987). Motor versus verbal recall of ballet sequences by young expert dancers. Journal of Sport and Exercise Psychology, 9 (3), 222-230.

Tenenbaum, G., Sar-El, T., Bar-Eli, M. (2000). Anticipation of ball location in low and high-skill performers: a developmental perspective. Psychology of Sport and Exercise, 1 (2), 117-128.

Tversky, A., Kahneman, D. (1981). The framing of decisions and the psychology of choice. Science, 211 (4481), 453-458.

Tzetzis, G., Lola, A.C. (2015). The effect of analogy, implicit, and explicit learning on anticipation in volleyball serving. International Journal of Sport Psychology, 46 (2), 152-166.

Tzetzis, G., Lola, C.A. (2010). The role of implicit, explicit instruction and their combination in learning anticipation skill, under normal and stress conditions. International Journal of Sport Sciences and Physical Education, 1, 54-59.

Vickers, J.N., Reeves, M.A., Chambers, K.L., Martell, S. (2004). 6 Decision training. Skill Acquisition in Sport: Research, Theory and Practice, 103.

Votsis, E., Tzetzis, G., Hatzitaki, V., Grouios, V.G. (2009). The effect of implicit and explicit methods in acquisition of anticipation skill in low and high complexity situations. International Journal of Sport Psychology, 40 (3), 374-391.

Ward, P., Williams, A.M., Bennett, S.J. (2002). Visual search and biological motion perception in tennis. Research Quarterly for Exercise and Sport, 73 (1), 107-112.

Williams, A M., Ward, P., Chapman, C. (2003). Training perceptual skill in field hockey: Is there transfer from the laboratory to the field?. Research quarterly for exercise and sport, 74 (1), 98-103.

Williams, A.M., Ward, P., Smeeton, N.J. (2004). Perceptual and cognitive expertise in sport. Skill acquisition in sport: Research, theory and practice, $15,328$.

Cite this article aS: Lola, A., Votsis, E., Tzetzis, G., Chatzopoulos, D. (2021). The Impact of Implicit and Explicit Training Methods on the Acquisition of Perceptual Expertise in Young Athletes. Central European Journal of Sport Sciences and Medicine, 3 (35), 87-98. DOI: 10.18276/cej.2021.3-08. 